\title{
Genótipos de trigo em diferentes densidades de semeadura ${ }^{1}$
}

\author{
Luís César Vieira Tavares², José Salvador Simoneti Foloni², \\ Manoel Carlos Bassoi ${ }^{2}$, Cássio Egídio Cavenaghi Prete ${ }^{3}$
}

\begin{abstract}
Wheat genotypes under different seeding rates

The wheat tillering capacity defines yield and yield components, being affected by seeding rate. This study aimed at evaluating wheat genotypes under different seeding rates, in Londrina and Ponta Grossa, Paraná State, Brazil, in 2009 and 2010. A completely randomized blocks design, in a factorial scheme, with four replications, was used. The agronomic traits of three wheat genotypes (PF 014384, BRS Tangará and BRS Pardela) were evaluated under the seeding rates of $150 \mathrm{pl} \mathrm{m}^{-2}$, $250 \mathrm{pl} \mathrm{m}^{-2}, 350 \mathrm{pl} \mathrm{m}^{-2}$ and $450 \mathrm{pl} \mathrm{m}^{-2}$. In Londrina, the maximum yield was observed at densities close to $270 \mathrm{pl} \mathrm{m}^{-2}$, while in Ponta Grossa (2009) there was a linear fit. There was no adjustment for plant height, concerning seeding rate. The number of ears per area $\left(\right.$ ears $\mathrm{m}^{-2}$ ) was higher in Ponta Grossa (2009) and did not differ between the locations, in 2010. In Ponta Grossa (2010), the highest one thousand seeds weight was estimated at the density of $341 \mathrm{pl} \mathrm{m}^{-2}$, while in Londrina (2010) it was estimated at $150 \mathrm{pl} \mathrm{m}^{-2}$ and $450 \mathrm{pl} \mathrm{m}^{-2}$. The seeding rate affected grain yield, depending on place and year. In Londrina, there was a limit for yield, concerning seeding rate. The one thousand seeds weight was influenced by seeding rate, depending on year and location. Plant height was affected by genotype and growing area.
\end{abstract}

KEY-WORDS: Triticum aestivum L.; grain yield; plant population.

\section{INTRODUÇ̃̃O}

O trigo (Triticum spp.) é uma das mais antigas culturas exploradas pelo homem e um dos principais cereais cultivados no mundo, com produção anual de, aproximadamente, 650 milhões de toneladas (USDA 2012). No Brasil, o volume produzido é de cerca de 5 milhões de toneladas (Conab 2012), sendo o seu consumo o dobro do volume produzido.

Devido ao fato de o trigo ser cultivado sob diversas condições edafoclimáticas, houve especial

\section{RESUMO}

A capacidade de perfilhamento em trigo define os componentes de rendimento e a produtividade, sendo afetada pela densidade de semeadura. Objetivou-se, neste estudo, avaliar genótipos de trigo cultivados em diferentes densidades de semeadura, em Londrina e Ponta Grossa (PR), nos anos de 2009 e 2010. Utilizou-se o delineamento experimental em blocos ao acaso, em esquema fatorial, com quatro repetições. Foram avaliados os aspectos agronômicos de três genótipos de trigo (PF 014384, BRS Tangará e BRS Pardela), nas densidades de semeadura de $150 \mathrm{pl} \mathrm{m}{ }^{-2}, 250 \mathrm{pl} \mathrm{m}{ }^{-2}, 350 \mathrm{pl} \mathrm{m}^{-2}$ e $450 \mathrm{pl} \mathrm{m}^{-2}$. Em Londrina, a máxima produtividade foi obtida em densidade próxima a $270 \mathrm{pl} \mathrm{m}^{-2}$, enquanto, em Ponta Grossa (2009), houve ajuste linear. Não ocorreu ajuste para altura de plantas, devido à densidade de semeadura. $\mathrm{O}$ número de espigas por área (espigas $\mathrm{m}^{-2}$ ) foi superior em Ponta Grossa (2009) e não diferiu entre os locais, em 2010. Em Ponta Grossa (2010), a maior massa de mil sementes estimada foi na densidade de $341 \mathrm{pl} \mathrm{m}^{-2} \mathrm{e}$, em Londrina (2010), nas densidades de $150 \mathrm{pl} \mathrm{m}^{-2}$ e $450 \mathrm{pl} \mathrm{m}^{-2}$. A densidade de semeadura influenciou na produtividade de grãos, dependendo do local e ano. Em Londrina, houve limite, quanto à densidade de semeadura, para a produtividade. A massa de mil sementes foi influenciada pela densidade de semeadura, dependendo do ano e local. A altura de plantas foi afetada pelo genótipo e local de cultivo.

PALAVRAS-CHAVE: Triticum aestivum L.; produtividade de grãos; população de plantas.

atenção ao desenvolvimento de novas cultivares adaptadas a diferentes regiões tritícolas. Além disto, mesmo que a planta de trigo apresente certa plasticidade dos componentes de rendimento, em resposta às condições climáticas das diferentes regiões de cultivo, a produtividade é influenciada pelas condições de clima (Cunha et al. 2009, Franceschi et al. 2010, Silva et al. 2011).

Nesse contexto, o cultivo de trigo sob diferentes condições ambientais expõe os genótipos à interação genótipo x ambiente (Yan \& Holland

1. Trabalho recebido em jul./2013 e aceito para publicação em jun./2014 (nº registro: PAT 25425).

2. Empresa Brasileira de Pesquisa Agropecuária (Embrapa), Embrapa Soja, Brasília, DF, Brasil.

E-mails: luiscesar.tavares@embrapa.br, salvador.foloni@embrapa.br, manoel.bassoi@embrapa.br.

3. Universidade Estadual de Londrina (UEL), Centro de Ciências Agrárias, Departamento de Agronomia, Londrina, PR, Brasil.

E-mail: cassio@uel.br. 
2010). Os efeitos desta interação podem ocorrer entre regiões, épocas de semeadura em um mesmo local, ou mesmo entre os diferentes anos de cultivo (Caierão et al. 2006, Cargnin et al. 2006, Franceschi et al. 2010, Silva et al. 2011).

Outro fator decisivo para a cultura do trigo é a densidade de semeadura, pois esta pode propiciar melhor equilíbrio dos componentes de rendimento, resultando em melhor produtividade (Valério et al. 2008, Benin et al. 2012). A densidade de semeadura é importante, principalmente, devido à diferença na capacidade de perfilhamento das cultivares (Sparkes et al. 2006, Silveira et al. 2010, Fioreze et al. 2012, Valério et al. 2013).

Há diferenças na capacidade de perfilhamento entre genótipos, conforme a densidade de semeadura, sendo observada maior competitividade intraplanta e interplanta, quando ocorre baixa e elevada densidade de semeadura, respectivamente. O efeito da competição entre plantas é determinante na produção de perfilhos e implica, diretamente, na produtividade de grãos e seus componentes (Ozturk et al. 2006). As cultivares com alto potencial de perfilhamento apresentam capacidade superior na manutenção da elevada produtividade de grãos, quando cultivadas em baixa densidade de semeadura (Whaley et al. 2000, Valério et al. 2009).

A adequação da densidade de semeadura, em função de genótipos e ambiente, propicia redução na competição e contribui para o incremento da produtividade de grãos de novas cultivares. Assim, este estudo objetivou avaliar genótipos de trigo, sob diferentes densidades de semeadura, durante dois anos, em duas regiões tritícolas do Paraná.

\section{MATERIAL E MÉTODOS}

Foram conduzidos experimentos em dois locais, nos anos agrícolas de 2009 e 2010 . Um deles foi instalado em área experimental da Embrapa Soja, em Londrina (PR) $\left(23^{\circ} 11^{\prime} 37^{\prime}\right.$ S, 51 ${ }^{\circ} 11^{\prime} 03^{\prime} \mathrm{W}$ e $630 \mathrm{~m}$ de altitude), com clima predominante do tipo Cfa, descrito como subtropical úmido com verão quente, em Latossolo Vermelho distroférrico. O outro experimento foi instalado em área experimental da Embrapa Produtos e Mercados, em Ponta Grossa (PR)

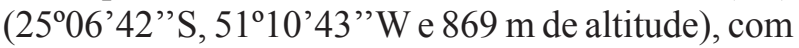
clima predominante do tipo $\mathrm{Cfb}$, descrito como clima temperado, em Latossolo Vermelho distroférrico. As características químicas dos solos são apresentadas na Tabela 1.

Foi utilizado o delineamento experimental de blocos ao acaso, em esquema fatorial, com quatro repetições, sendo avaliados três genótipos de trigo (PF 014384, BRS Tangará e BRS Pardela), manejados nas seguintes densidades de semeadura: $150 \mathrm{pl} \mathrm{m}^{-2}$, $250 \mathrm{pl} \mathrm{m}^{-2}, 350 \mathrm{pl} \mathrm{m}^{-2}$ e $450 \mathrm{pl} \mathrm{m}^{-2}$. Cada unidade experimental foi composta por seis linhas, espaçadas em 0,17 m entre si, com 6,0 m de comprimento. $\mathrm{O}$ espaçamento entre as parcelas foi de $0,75 \mathrm{~m}$ e entre os blocos de 1,0 m. Foram considerados, como área útil de cada parcela, as seis linhas e 5,5 m de comprimento, totalizando $5,61 \mathrm{~m}^{2}$.

A semeadura foi feita com uma semeadora de parcelas, sendo que, após a emergência, foi realizada a contagem do número de plantas, para fins de monitoramento da uniformidade da população de plantas, sendo ajustada por meio de desbaste, quando necessário. Em Londrina, a semeadura foi realizada em 16/05/2009 e 19/04/2010, enquanto, em Ponta

Tabela 1. Características químicas do solo, por local (Londrina e Ponta Grossa, PR, 2009).

\begin{tabular}{|c|c|c|c|c|c|}
\hline \multirow{3}{*}{ Característica } & \multirow{3}{*}{ Unidade } & \multicolumn{4}{|c|}{ Profundidade } \\
\hline & & $00-10 \mathrm{~cm}$ & $10-20 \mathrm{~cm}$ & $00-10 \mathrm{~cm}$ & $10-20 \mathrm{~cm}$ \\
\hline & & \multicolumn{2}{|c|}{ Londrina } & \multicolumn{2}{|c|}{ Ponta Grossa } \\
\hline $\mathrm{pH}\left(\mathrm{CaCl}_{2}\right)$ & & 5,46 & 5,17 & 5,57 & 5,03 \\
\hline $\mathrm{Ca}^{+2}$ & & 5,34 & 8,23 & 5,78 & 5,88 \\
\hline $\mathrm{Mg}^{+2}$ & & 1,87 & 1,66 & 2,04 & 2,08 \\
\hline $\mathrm{K}^{+}$ & $\mathrm{cmol}_{\mathrm{c}} \mathrm{dm}^{-3}$ & 0,68 & 0,16 & 0,19 & 0,16 \\
\hline $\mathrm{Al}^{+3}$ & & 0,08 & 0,04 & 0,02 & 0,04 \\
\hline $\mathrm{H}+\mathrm{Al}$ & & 3,25 & 5,93 & 4,39 & 5,93 \\
\hline CTC & & 11,14 & 14,85 & 12,39 & 14,05 \\
\hline $\mathrm{V}$ & $\%$ & 70,83 & 67,34 & 64,50 & 57,75 \\
\hline $\mathrm{C}$ & $\mathrm{g} \mathrm{dm}^{-3}$ & 7,11 & 9,65 & 12,86 & 13,50 \\
\hline $\mathrm{P}$ & $\mathrm{mg} \mathrm{dm}{ }^{-3}$ & 47,42 & 30,58 & 12,57 & 6,09 \\
\hline
\end{tabular}


Grossa, foi realizada em 07/07/2009 e 15/07/2010. A adubação de base foi feita com $300 \mathrm{~kg} \mathrm{ha}^{-1}$ do adubo formulado 08-28-16 (NPK). Foi efetuada adubação de cobertura na dose de $40 \mathrm{~kg} \mathrm{ha}^{-1}$ de nitrogênio (sulfato de amônio), no início do perfilhamento da cultura.

Foram realizadas as seguintes avaliações: 1) Altura de plantas: na maturação, foram medidas 15 plantas por unidade experimental, do solo ao ápice da espiga, excluindo-se as aristas; 2) Massa de mil grãos: massa de 1.000 grãos (g) tomados ao acaso, em cada parcela, corrigida para $13 \%$ de umidade; 3 ) Peso hectolítrico: determinado em balança de $0,25 \mathrm{~L}\left(\mathrm{~kg} \mathrm{hL}^{-1}\right)$, com correção para $13 \%$ de umidade; 4) Número de espigas por unidade de área: obtido pela contagem do número de espigas $\mathrm{m}^{-2}$; 5) Produtividade de grãos: produção de grãos da área útil de cada unidade experimental, que, após colhidos e trilhados, foram pesados, sendo estimada a produtividade de grãos em $\mathrm{kg} \mathrm{ha}^{-1}$, com umidade de $13 \%$.

Foi realizada a verificação das pressuposições do modelo matemático (homogeneidade da variância dos erros e normalidade da distribuição dos erros estimados). Posteriormente, foi efetuada análise de variância conjunta (Anava), para detectar, pelo teste $\mathrm{F}$, as significâncias dos efeitos de cultivares, manejo da densidade de semeadura, ano e local de experimentação. Foi realizada a comparação de médias pelo teste Tukey, a 5\%, bem como análise de regressão, para o efeito da densidade de semeadura.

\section{RESULTADOS E DISCUSSÃO}

Os resultados da análise de variância (Anava) demonstraram que, para a produtividade de grãos (PG), todos os efeitos isolados foram significativos $(\mathrm{p}<0,01)$. O local de cultivo não influenciou $(\mathrm{p}>0,05)$ o número de espigas por área (NEA). Além disto, para a variável NEA, o efeito de cultivares foi não significativo $(p>0,05)$. A densidade de semeadura não influenciou as variáveis massa de mil sementes, peso hectolítrico e altura de planta (Tabela 2). As variáveis peso hectolítrico e número de espigas por área foram influenciadas, significativamente $(\mathrm{p}<0,01)$, pelas interações ano x local (para ambas as variáveis) e ano x cultivar (peso hectolítrico). Para as demais variáveis, o estudo foi baseado nas interações triplas significativas.

Em 2009, a PG, em Londrina, foi inferior apenas para o genótipo PF014384, enquanto, em 2010, foi superior para todos os genótipos (Tabela 3). Em 2009, as médias dos genótipos, em Londrina, não

Tabela 2. Resultado da análise de variância conjunta para a altura de plantas (AP), produtividade de grãos (PG), massa de mil sementes (MMS), peso hectolítrico ( $\mathrm{PH})$ e número de espigas por área (NEA), para genótipos de trigo cultivados em diferentes densidades de semeadura (Londrina e Ponta Grossa, PR, 2009 e 2010).

\begin{tabular}{|c|c|c|c|c|c|}
\hline \multirow{2}{*}{ Fonte de variação } & \multicolumn{5}{|c|}{ Característica } \\
\hline & $\mathrm{AP}$ & $\mathrm{PG}$ & MMS & $\mathrm{PH}$ & NEA \\
\hline \multicolumn{6}{|l|}{ Bloco (Local) } \\
\hline Bloco (Local) & 0,1491 & 0,033 & 0,040 & 0,1038 & $<0,001$ \\
\hline Ano (A) $)_{(\mathrm{GL} 1)}$ & 0,0117 & $<0,001$ & $<0,001$ & $<0,001$ & $<0,001$ \\
\hline Local (L) & 0,0022 & $<0,001$ & $<0,001$ & $<0,001$ & 0,0633 \\
\hline Cultivar (C) & $<0,001$ & $<0,001$ & $<0,001$ & $<0,001$ & 0,3092 \\
\hline Densidade (D) & 0,9316 & $<0,001$ & 0,2556 & 0,4325 & $<0,001$ \\
\hline $\mathrm{A} * \mathrm{~L}_{(\mathrm{GL} 1)}$ & 0,7293 & $<0,001$ & 0,0459 & $<0,001$ & 0,0046 \\
\hline$A * C_{(\mathrm{GL} 2)}^{(\mathrm{GL} 1)}$ & $<0,001$ & $<0,001$ & $<0,001$ & $<0,001$ & 0,4095 \\
\hline $\mathrm{L} * \mathrm{C}_{(\mathrm{GL} 2)}^{(\mathrm{GL} 2)}$ & $<0,001$ & $<0,001$ & $<0,001$ & 0,1501 & 0,3145 \\
\hline $\mathrm{A} * \mathrm{D}_{(\mathrm{GL} 3)}$ & 0,3147 & 0,053 & 0,1899 & 0,4923 & 0,1726 \\
\hline $\mathrm{L} * \mathrm{D}_{(\mathrm{GL} 3)}^{(\mathrm{GL} 3)}$ & 0,0122 & $<0,001$ & 0,1702 & 0,9247 & 0,3248 \\
\hline $\mathrm{C} * \mathrm{D}_{(\mathrm{GL} 6)}^{(\mathrm{GL} 3)}$ & 0,1241 & 0,6846 & 0,6697 & 0,3871 & 0,5572 \\
\hline $\mathrm{A} * \mathrm{~L} * \mathrm{C}$ & 0,1613 & $<0,001$ & $<0,001$ & 0,1825 & 0,4805 \\
\hline $\mathrm{A} * \mathrm{~L} * \mathrm{D}$ & 0,4354 & 0,0234 & 0,031 & 0,2191 & 0,7377 \\
\hline $\mathrm{A} * \mathrm{C} * \mathrm{D}(\mathrm{GL})$ & 0,0716 & 0,1941 & 0,5347 & 0,2516 & 0,2807 \\
\hline $\mathrm{L} * \mathrm{C} * \mathrm{D} \underset{(\mathrm{GL} 6)}{(\mathrm{GL} 6)}$ & 0,0175 & 0,1051 & 0,0084 & 0,6487 & 0,1606 \\
\hline $\mathrm{A} * \mathrm{~L} * \mathrm{C} * \mathrm{D}_{(\mathrm{GL} 6)}$ & 0,9363 & 0,2357 & 0,1506 & 0,8614 & 0,7492 \\
\hline QM Resíduo $_{\text {(GL 132) }}$ & 5,93 & 92351 & 1,48 & 1,09 & 8570 \\
\hline Média & 82,00 & 3882 & 35,40 & 79,50 & 432 \\
\hline CV (\%) & 2,95 & 7,82 & 3,44 & 1,31 & 22,91 \\
\hline
\end{tabular}


diferiram entre si, enquanto, em Ponta Grossa, o genótipo PF014384 apresentou a maior produtividade de grãos. Para o cultivo em Londrina, em 2010, o genótipo PF014384 apresentou a maior produtividade de grãos, enquanto, para a condição ambiental de Ponta Grossa (2010), os genótipos PF014384 e BRS Tangará foram os mais produtivos. Além disto, ficou evidente que o efeito dos anos foi significativo em ambas as localidades e para todos os genótipos testados. Portanto, para o cultivo em Londrina e em Ponta Grossa, o ano de 2010 propiciou a maior média produtiva, para todas as cultivares.

O cultivo em 2010 resultou em produtividade de grãos significativamente superior, em ambas as localidades, bem como em todas as densidades de semeadura (Tabela 4). Não ocorreu efeito de local para o cultivo no ano 2009 e densidade de semeadura de $350 \mathrm{pl} \mathrm{m}^{-2}$. Em 2009 e na densidade de $450 \mathrm{pl} \mathrm{m}^{-2}$, a produtividade de grãos foi superior para o cultivo em Ponta Grossa. Nas demais densidades, em ambos os anos, o cultivo em Londrina apresentou produtividade de grãos superior à observada em Ponta Grossa.

Para o cultivo em Londrina, houve ajuste quadrático da produtividade de grãos, sendo a máxima produtividade obtida nas densidades de $269 \mathrm{pl} \mathrm{m}^{-2}$ e $274 \mathrm{pl} \mathrm{m}^{-2}$, respectivamente nos anos de 2009 e 2010. Portanto, a melhor densidade de semeadura para Londrina foi aquela próxima a $270 \mathrm{pl} \mathrm{m}^{-2}$. Em Ponta Grossa (2009), houve ajuste linear para a pro- dutividade de grãos, em decorrência das densidades de semeadura, enquanto, em 2010, não foi observado efeito de densidades de semeadura (Figura 1).

A produtividade de grãos é de caráter complexo, com diferentes componentes, sendo que diversos fatores a condicionam, dentre os quais a origem genética e o efeito ambiental. Além disto, a expressão do potencial de rendimento de grãos de um genótipo, em uma região, depende de fatores genéticos e ambientais.

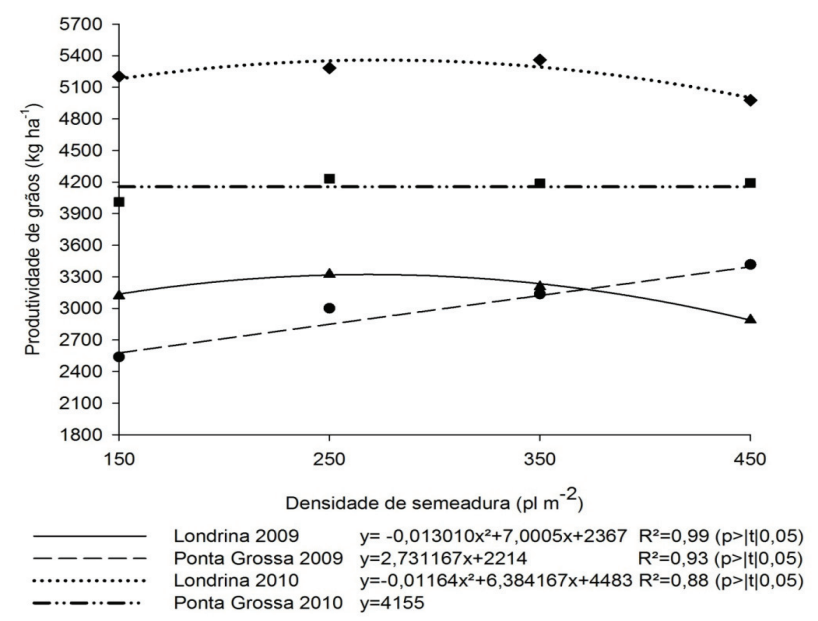

Figura 1. Médias de produtividade de grãos $\left(\mathrm{kg} \mathrm{ha}^{-1}\right) \mathrm{de}$ três genótipos de trigo, cultivados em diferentes densidades de semeadura (Londrina e Ponta Grossa, PR, 2009 e 2010).

Tabela 3. Médias de produtividade de grãos $\left(\mathrm{kg} \mathrm{ha}^{-1}\right)$ dos genótipos de trigo PF014384, BRS Tangará, BRS Pardela, por local (Londrina e Ponta Grossa, PR, 2009 e 2010).

\begin{tabular}{lcccc}
\hline \multirow{2}{*}{ Genótipo } & \multicolumn{2}{c}{2009} & \multicolumn{2}{c}{2010} \\
\cline { 2 - 5 } & Londrina & Ponta Grossa & $5.476 \mathrm{aA} \underline{\mathrm{a}}$ & Ponta Grossa \\
\hline PF014384 & $3.011 \mathrm{aB} \underline{\mathrm{b}}$ & $3.852 \mathrm{aA} \underline{\mathrm{b}}$ & $5.144 \mathrm{abB} \underline{\mathrm{a}}$ \\
BRS Tangará & $3.169 \mathrm{aA} \underline{\mathrm{b}}$ & $2.525 \mathrm{bB} \underline{\mathrm{b}}$ & $5.215 \mathrm{bA} \underline{\mathrm{a}}$ & $4.394 \mathrm{aB} \underline{\mathrm{a}}$ \\
BRS Pardela & $3.221 \mathrm{aA} \underline{\mathrm{b}}$ & $2.722 \mathrm{bB} \underline{\mathrm{b}}$ & $4.925 \mathrm{cA} \underline{\mathrm{a}}$ & $3.929 \mathrm{bB} \underline{\mathrm{a}}$ \\
\hline
\end{tabular}

Letras maiúsculas, na coluna, comparam diferentes locais, no mesmo tratamento. Letras minúsculas sublinhadas, na mesma linha, comparam o mesmo local (município), nos diferentes anos. Letras minúsculas, na mesma linha, comparam os diferentes municípios (locais), no mesmo ano. Médias seguidas de mesma letra não diferem entre si, pelo Teste Tukey, a $5 \%$.

Tabela 4. Médias de produtividade de grãos de genótipos de trigo, por local, em cada densidade de semeadura (Londrina e Ponta Grossa, PR, 2009 e 2010).

\begin{tabular}{|c|c|c|c|c|c|c|c|c|}
\hline \multirow{3}{*}{ Local } & \multicolumn{8}{|c|}{ Densidade de semeadura $\left(\mathrm{pl} \mathrm{m}^{-2}\right)$} \\
\hline & \multicolumn{2}{|c|}{150} & \multicolumn{2}{|c|}{250} & \multicolumn{2}{|c|}{350} & \multicolumn{2}{|c|}{450} \\
\hline & 2009 & 2010 & 2009 & 2010 & 2009 & 2010 & 2009 & 2010 \\
\hline Londrina & $3.129 \mathrm{aB}$ & $5.023 \mathrm{aA}$ & $3.337 \mathrm{aB}$ & $5.116 \mathrm{aA}$ & $3.214 \mathrm{aB}$ & $5.177 \mathrm{aA}$ & $2.895 \mathrm{bB}$ & $4.813 \mathrm{aA}$ \\
\hline Ponta Grossa & $2.492 \mathrm{bB}$ & $3.936 \mathrm{bA}$ & $2.992 \mathrm{bB}$ & $4.160 \mathrm{bA}$ & $3.092 \mathrm{aB}$ & $4.125 \mathrm{bA}$ & $3.368 \mathrm{aB}$ & $4.131 \mathrm{bA}$ \\
\hline
\end{tabular}

Letras minúsculas comparam entre linhas (locais) e letras maiúsculas comparam entre colunas (anos). Médias seguidas de mesma letra não diferem entre si, pelo Teste Tukey, a $5 \%$. 
Nesse sentido, Cargnin et al. (2006) e Silva et al. (2011) também observaram efeito do ambiente de cultivo na produtividade de grãos. Além disto, a maior produtividade observada em Londrina, em relação a Ponta Grossa, também já foi relatada por Franceschi et al. (2010). Tais resultados confirmam o efeito significativo do ano e local de cultivo (condição ambiental) para a produtividade de grãos, principalmente porque, em 2009, as condições climáticas foram desfavoráveis.

Considerando-se condições climáticas adequadas, em Ponta Grossa (2010), é desnecessário o uso de mais que 150 sementes viáveis $\mathrm{m}^{-2}$. No caso de Londrina, independentemente da condição climática, a densidade de semeadura ideal é de, aproximadamente, $270 \mathrm{pl} \mathrm{m}^{-2}$. Estes valores são importantes, porque o aumento do número de sementes por unidade de área implica em maior custo de produção, além de aumento na predisposição das plantas ao acamamento.

Além disso, observou-se que a produtividade de grãos variou, significativamente, em uma mesma densidade de semeadura, conforme o ano de cultivo. Tal resultado ressalta a importância do efeito do ano e da interação entre o ano e as práticas de manejo, na produtividade do trigo. Estresses causados por excesso de água no solo afetam, de forma negativa, o desenvolvimento da planta, com efeito direto na produtividade final, na cultura do trigo (Guarienti et al. 2005). Portanto, a forma mais eficiente que o produtor dispõe para reduzir estes riscos é o emprego de práticas de manejo das culturas, tais como a escolha da cultivar e da época de semeadura (Silva et al. 2011), bem como a densidade de semeadura adequada.

O genótipo PF 014384 apresentou a maior altura de plantas, para o cultivo em Londrina, nas densidades de semeadura de $150 \mathrm{pl} \mathrm{m}^{-2}$ e $350 \mathrm{pl} \mathrm{m}^{-2}$, sendo que, nas densidades de $250 \mathrm{pl} \mathrm{m}^{-2}$ e $450 \mathrm{pl} \mathrm{m}^{-2}$, não se diferenciou da cultivar BRS Tangará (Tabela 5). Já em Ponta Grossa, a cultivar que apresentou a maior altura de planta, em todas as densidades de semeadura, foi a BRS Tangará.

Não foi possível obter ajuste de regressão até a equação de segundo grau para a altura de plantas dos genótipos, em função das densidades de semeadura. De forma semelhante, Zagonel et al. (2002) relataram ausência de efeito da densidade de semeadura sobre a altura de plantas, em trigo. Por outro lado, o efeito ambiental significativo para a altura de plantas também foi observado por Cargnin et al. (2006), o que corrobora os resultados obtidos neste estudo.

O número de espigas por unidade de área (espigas $\mathrm{m}^{-2}$ ) foi maior no cultivo em Ponta Grossa (2009), ao passo que não diferiu entre as localidades, no ano 2010. Em ambas as localidades, o número de espigas por unidade de área foi superior no primeiro ano de experimentação (Tabela 6). Além disto, o número de espigas por unidade de área foi influenciado pelo efeito da densidade de semeadura, apresentando ajuste linear crescente (Figura 2).

Segundo Ozturk et al. (2006), a genética é determinante na definição da resposta das plantas à densidade de semeadura, quanto ao potencial de emissão de espigas. De maneira semelhante, Valério et al. (2008) observaram que a emissão de espigas apresentou resposta diferenciada às densidades de semeadura, para cada cultivar. Entretanto, no presente

Tabela 6. Médias do número de espigas por unidade de área (espigas $\mathrm{m}^{-2}$ ) de três genótipos de trigo, por local (Londrina e Ponta Grossa, PR, 2009 e 2010).

\begin{tabular}{lcc}
\hline \multicolumn{1}{c}{ Local } & 2009 & 2010 \\
\hline Londrina & $464 \mathrm{bA}$ & $374 \mathrm{aB}$ \\
Ponta Grossa & $528 \mathrm{aA}$ & $361 \mathrm{aB}$ \\
\hline
\end{tabular}

Letras minúsculas comparam entre linhas (locais) e letras maiúsculas comparam entre colunas (anos). Médias seguidas de mesma letra não diferem entre si, pelo Teste Tukey, a 5\%.

Tabela 5. Altura de plantas (cm) dos genótipos de trigo PF014384, BRS Pardela e BRS Tangará, por local, em cada densidade de semeadura, na média de dois anos (Londrina e Ponta Grossa, PR, 2009 e 2010).

\begin{tabular}{lcccccccc}
\hline \multirow{2}{*}{ Genótipo } & \multicolumn{7}{c}{ Densidade de semeadura $\left(\mathrm{pl} \mathrm{m}^{-2}\right)$} \\
\cline { 2 - 8 } & \multicolumn{2}{c}{150} & \multicolumn{2}{c}{250} & \multicolumn{2}{c}{350} & 450 \\
\cline { 2 - 8 } & Londrina & Ponta Grossa & Londrina & Ponta Grossa & Londrina & Ponta Grossa & Londrina & Ponta Grossa \\
\hline PF014384 & $87 \mathrm{aA}$ & $79 \mathrm{bB}$ & $84 \mathrm{aA}$ & $81 \mathrm{bB}$ & $88 \mathrm{aA}$ & $81 \mathrm{bB}$ & $86 \mathrm{aA}$ & $81 \mathrm{bB}$ \\
BRS Pardela & $79 \mathrm{cA}$ & $79 \mathrm{bA}$ & $77 \mathrm{bA}$ & $79 \mathrm{bA}$ & $80 \mathrm{cA}$ & $76 \mathrm{cB}$ & $79 \mathrm{bA}$ & $79 \mathrm{bA}$ \\
BRS Tangará & $82 \mathrm{bB}$ & $87 \mathrm{aA}$ & $84 \mathrm{aB}$ & $87 \mathrm{aA}$ & $83 \mathrm{bB}$ & $86 \mathrm{aA}$ & $84 \mathrm{aB}$ & $86 \mathrm{aA}$ \\
\hline
\end{tabular}

Letras minúsculas comparam entre linhas (cultivares) e letras maiúsculas comparam entre colunas (locais). Médias seguidas de mesma letra não diferem entre si, pelo Teste Tukey, a 5\%. 


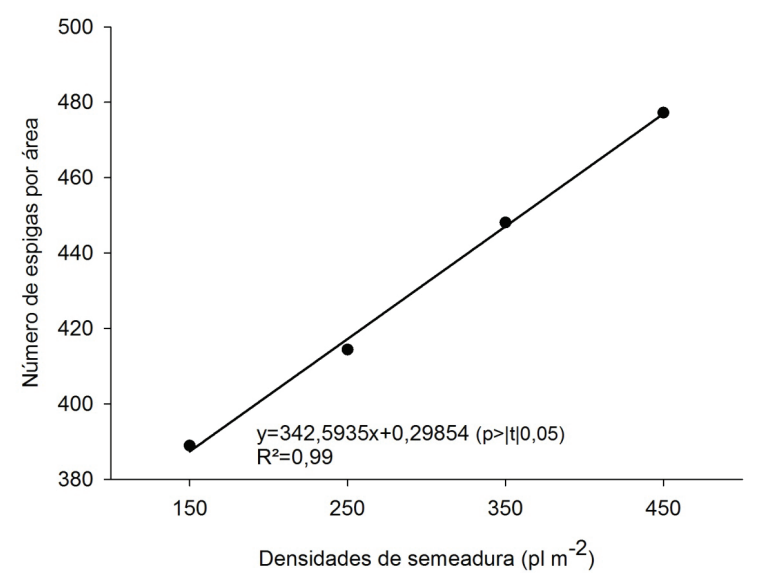

Figura 2. Médias do número de espigas por unidade de área (espigas $\mathrm{m}^{-2}$ ) de três genótipos de trigo, por local (Londrina e Ponta Grossa, PR, 2009 e 2010).

estudo, não houve efeito significativo da interação entre genótipos e densidades de semeadura, no número de espigas por unidade de área.

A cultivar BRS Tangará (2009 e 2010) e BRS Pardela (2010) apresentaram a maior massa de mil sementes, em Londrina (Tabela 7), enquanto o genótipo PF014384 apresentou a menor massa de mil sementes, no cultivo em Londrina (2009 e 2010). No cultivo em Ponta Grossa, as cultivares BRS Tangará e BRS Pardela apresentaram, respectivamente, a maior e menor massa de mil grãos, em 2009. Em
Ponta Grossa (2010), não foi observada diferença significativa na massa de mil sementes entre os genótipos. Em ambos os anos, o cultivo em Ponta Grossa apresentou a maior massa de mil sementes, para todas as cultivares. Além disto, para todos os genótipos, a massa de mil sementes foi maior no ano 2010, em ambas as regiões, exceto para a cultivar BRS Tangará, que não foi influenciada pelo ano de cultivo, em Londrina.

Em Ponta Grossa, a massa de mil sementes foi superior em todas as densidades de semeadura e nos dois anos de cultivo. Para o cultivo em Londrina, a massa de mil sementes foi superior em 2010, enquanto que, em Ponta Grossa, isto ocorreu apenas na densidade de $150 \mathrm{pl} \mathrm{m}^{-2}$, não tendo sido observada diferença entre os anos, sendo que, nas demais densidades de semeadura, a massa de mil sementes também foi superior em 2010 (Tabela 8).

A massa de mil sementes não foi influenciada pelas densidades de semeadura, em ambas as localidades, em 2009 (Figura 3). Por outro lado, em Ponta Grossa e Londrina (2010), ocorreu ajuste quadrático para a massa de mil sementes, em função das densidades de semeadura. Em Ponta Grossa, observou-se maior massa de mil sementes na densidade de $341 \mathrm{pl} \mathrm{m}^{-2}$. Por outro lado, para o cultivo em Londrina (2010), a massa de mil sementes mostrou-se superior nas densidades de $150 \mathrm{pl} \mathrm{m}^{-2} \mathrm{e} 450 \mathrm{pl} \mathrm{m}^{-2}$. As

Tabela 7. Médias da massa de mil sementes (g) dos genótipos PF014384, BRS Pardela e BRS Tangará, por local (Londrina e Ponta Grossa, PR, 2009 e 2010).

\begin{tabular}{lcccc}
\hline \multirow{2}{*}{ Genótipo } & \multicolumn{2}{c}{2009} & & 2010 \\
\cline { 2 - 5 } & Londrina & Ponta Grossa & Londrina & Ponta Grossa \\
\hline PF014384 & $28,6 \mathrm{cB} \underline{\mathrm{b}}$ & $37,7 \mathrm{bA} \underline{\mathrm{b}}$ & $30,6 \mathrm{bB} \underline{\mathrm{a}}$ & $38,9 \mathrm{aA} \underline{\mathrm{a}}$ \\
BRS Tangará & $34,1 \mathrm{aB} \underline{\mathrm{a}}$ & $43,3 \mathrm{aA} \underline{\mathrm{b}}$ & $34,4 \mathrm{aB} \underline{\mathrm{a}}$ & $38,9 \mathrm{aA} \underline{\mathrm{a}}$ \\
BRS Pardela & $31,4 \mathrm{bB} \underline{\mathrm{b}}$ & $32,8 \mathrm{cA} \underline{\mathrm{b}}$ & $34,4 \mathrm{aB} \underline{\mathrm{a}}$ & $39,1 \mathrm{aA} \underline{\mathrm{a}}$ \\
\hline
\end{tabular}

Letras minúsculas comparam entre linhas (cultivares) e letras maiúsculas comparam entre colunas (locais e anos). Letras maiúsculas, na coluna, comparam diferentes locais, no mesmo tratamento. Letras minúsculas sublinhadas, na mesma linha, comparam o mesmo local (município), nos diferentes anos. Letras minúsculas, na mesma linha, comparam os diferentes municípios (locais), no mesmo ano. Médias seguidas de mesma letra não diferem entre si, pelo Teste Tukey, a $5 \%$.

Tabela 8. Médias da massa de mil sementes (g) de três genótipos de trigo, por local, em cada densidade de semeadura (Londrina e Ponta Grossa, PR, 2009 e 2010).

\begin{tabular}{|c|c|c|c|c|c|c|c|c|}
\hline \multirow{3}{*}{ Local } & \multicolumn{8}{|c|}{ Densidade de semeadura $\left(\mathrm{pl} \mathrm{m}^{-2}\right)$} \\
\hline & \multicolumn{2}{|c|}{150} & \multicolumn{2}{|c|}{250} & \multicolumn{2}{|c|}{350} & \multicolumn{2}{|c|}{450} \\
\hline & 2009 & 2010 & 2009 & 2010 & 2009 & 2010 & 2009 & 2010 \\
\hline Londrina & $31,5 \mathrm{bB}$ & $33,6 \mathrm{bA}$ & $31,1 \mathrm{bB}$ & $33,0 \mathrm{bA}$ & $31,2 \mathrm{bB}$ & $32,6 \mathrm{bA}$ & $31,8 \mathrm{bB}$ & $33,4 \mathrm{bA}$ \\
\hline Ponta Grossa & $38,3 \mathrm{aA}$ & $37,9 \mathrm{aA}$ & $37,6 \mathrm{aB}$ & $39,6 \mathrm{aA}$ & $37,6 \mathrm{aB}$ & $39,2 \mathrm{aA}$ & $38,1 \mathrm{aB}$ & $39,3 \mathrm{aA}$ \\
\hline
\end{tabular}

Letras minúsculas comparam entre linhas (locais) e letras maiúsculas comparam entre colunas (anos). Médias seguidas de mesma letra não diferem entre si, pelo Teste Tukey, a $5 \%$ 


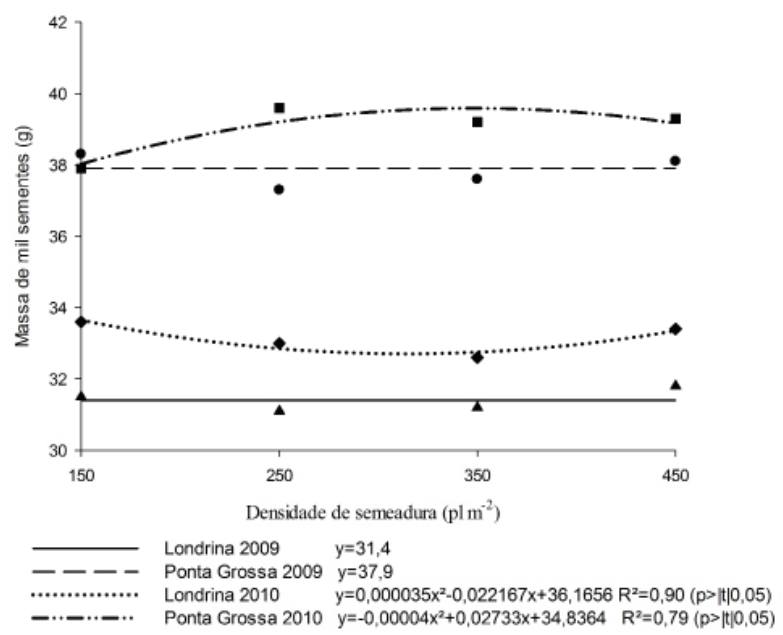

Figura 3. Médias da massa de mil sementes de três genótipos de trigo, em função da densidade de semeadura (Londrina e Ponta Grossa, PR, 2009 e 2010).

mudanças na massa de mil sementes são observadas porque a planta de trigo é bastante plástica, em relação ao efeito de densidades de semeadura (Valério et al. 2008). Contudo, a amplitude das alterações na massa de mil sementes não é elevada, porque esta é uma característica controlada geneticamente (Guarienti 2005).

Em Londrina, a maior massa de mil sementes foi observada para a cultivar BRS Tangará, exceto nas densidades de $250 \mathrm{pl} \mathrm{m}^{-2}$ e $450 \mathrm{pl} \mathrm{m}^{-2}$, nas quais não diferiu da cultivar BRS Pardela. No cultivo em Ponta Grossa, a cultivar BRS Tangará apresentou a maior massa de mil grãos, em todas as densidades de semeadura. Em todas as densidades de semeadura e para todos os genótipos estudados, o cultivo em Ponta Grossa propiciou maior massa de mil sementes (Tabela 9).

No cultivo realizado em Ponta Grossa, para todas os genótipos, não foi observado efeito de densidades de semeadura sobre a massa de mil sementes.
Por outro lado, no cultivo em Londrina, apenas a cultivar BRS Tangará foi influenciada pelo efeito de densidade de semeadura, sendo que a menor e a maior densidades de semeadura propiciaram a maior massa de mil sementes (Figura 4).

A menor massa de mil sementes para os genótipos, em 2009, deve-se ao excesso hídrico, principalmente na fase de maturação das plantas. Guarienti et al. (2005) relataram que o excesso hídrico está relacionado a reduções na massa de mil sementes. Os mesmos autores observaram redução significativa nesta característica, para o trigo, quando há excesso hídrico de 40 dias até o dia anterior à colheita.

A ocorrência de temperaturas amenas, em Ponta Grossa, é a principal causa da maior massa de mil sementes, nesta localidade. Em condições de temperatura amena, há redução no metabolismo da

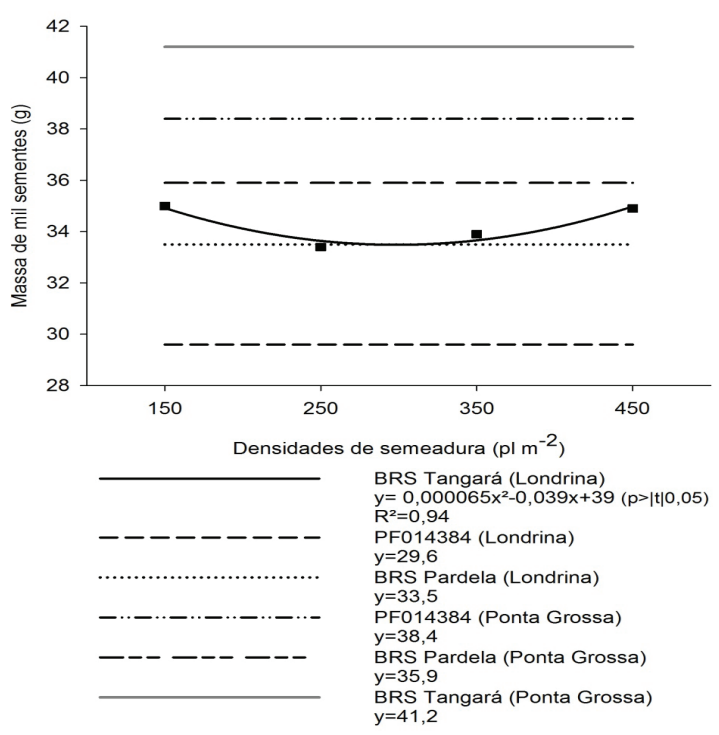

Figura 4. Massa de mil sementes ( $\mathrm{g}$ ) dos genótipos de trigo PF014384, BRS Pardela e BRS Tangará, em função da densidade de semeadura, na média dos anos (Londrina e Ponta Grossa, PR, 2009 e 2010).

Tabela 9. Médias da massa de mil sementes (g) dos genótipos de trigo PF014384, BRS Pardela e BRS Tangará, por local, em cada densidade de semeadura (Londrina e Ponta Grossa, PR, 2009 e 2010).

\begin{tabular}{|c|c|c|c|c|c|c|c|c|}
\hline \multirow{3}{*}{ Genótipo } & \multicolumn{8}{|c|}{ Densidade de semeadura $\left(\mathrm{pl} \mathrm{m}^{-2}\right)$} \\
\hline & \multicolumn{2}{|c|}{150} & \multicolumn{2}{|c|}{250} & \multicolumn{2}{|c|}{350} & \multicolumn{2}{|c|}{450} \\
\hline & Londrina & Ponta Grossa & Londrina & Ponta Grossa & Londrina & Ponta Grossa & Londrina & Ponta Grossa \\
\hline PF 014384 & $30,3 \mathrm{cB}$ & $37,8 \mathrm{bA}$ & $29,3 \mathrm{bB}$ & $38,8 \mathrm{bA}$ & $29,4 \mathrm{cB}$ & $38,5 \mathrm{bA}$ & $29,4 \mathrm{bB}$ & $38,3 \mathrm{bA}$ \\
\hline BRS Pardela & $32,4 \mathrm{bB}$ & $36,1 \mathrm{cA}$ & $33,5 \mathrm{aB}$ & $35,4 \mathrm{cA}$ & $32,4 \mathrm{cB}$ & $35,9 \mathrm{cA}$ & $33,5 \mathrm{aB}$ & $36,3 \mathrm{cA}$ \\
\hline BRS Tangará & $35,0 \mathrm{aB}$ & $40,5 \mathrm{aA}$ & $33,4 \mathrm{aB}$ & $41,8 \mathrm{aA}$ & $33,9 \mathrm{aB}$ & $40,8 \mathrm{aA}$ & $34,9 \mathrm{aB}$ & $41,5 \mathrm{aA}$ \\
\hline
\end{tabular}

Letras minúsculas comparam entre linhas (genótipos) e letras maiúsculas comparam entre colunas (locais). Médias seguidas de mesma letra não diferem entre si, pelo Teste Tukey, a $5 \%$. 
Tabela 10. Médias do peso hectolítrico $\left(\mathrm{kg} \mathrm{hL}^{-1}\right)$ por local ou por genótipo (Londrina e Ponta Grossa, PR, 2009 e 2010).

\begin{tabular}{ccc}
\hline Local & 2009 & 2010 \\
\hline Londrina & $74,3 \mathrm{bB}$ & $87,3 \mathrm{aA}$ \\
Ponta Grossa & $76,6 \mathrm{aB}$ & $79,6 \mathrm{bA}$ \\
\hline Cultivar & 2009 & 2010 \\
\hline PF014384 & $74,8 \mathrm{bB}$ & $83,9 \mathrm{aA}$ \\
BRS Tangará & $75,1 \mathrm{bB}$ & $82,7 \mathrm{bA}$ \\
BRS Pardela & $76,6 \mathrm{aB}$ & $83,8 \mathrm{aA}$ \\
\hline
\end{tabular}

Letras minúsculas comparam entre linhas (locais e genótipos) e letras maiúsculas comparam entre colunas (anos). Médias seguidas de mesma letra não diferem entre si, pelo Teste Tukey, a 5\%.

planta e maior período de enchimento de grãos, o que resulta em maior massa de mil sementes (Gaju et al. 2009).

O peso hectolítrico $(\mathrm{PH})$ foi superior em Ponta Grossa, em 2009, e em Londrina, em 2010. Com relação ao efeito dos anos, observou-se que as condições climáticas de 2010 propiciaram maior PH em ambas as localidades (Tabela 10). Quanto à interação cultivar x ano, observou-se que os genótipos BRS Pardela (2009 e 2010) e PF014384 (2010) apresentaram maior PH. O efeito dos anos foi significativo para o $\mathrm{PH}$, para todas as cultivares, sendo que o ano de 2010 propiciou $\mathrm{PH}$ superior ao verificado em 2009.

Assim como observado para a massa de mil sementes, o peso hectolítrico também foi afetado pelas condições ambientais, especialmente pela precipitação pluvial. Guarienti et al. (2005) relataram que, nos 20 dias que antecedem a colheita, há redução significativa do peso hectolítrico, em função do excesso hídrico. Portanto, a diminuição do peso hectolítrico pode ser atribuída às sucessivas mudanças na umidade do grão, devido à sequência de chuva e período seco ocorrida em 2009.

\section{CONCLUSÕES}

1. A altura de plantas foi influenciada isoladamente pelos efeitos do genótipo, local e ano de cultivo.

2. A densidade de semeadura exerceu efeito na produtividade de grãos, dependendo do local e do ano de cultivo.

3. O cultivo em Londrina apresentou limite definido, quanto à densidade de semeadura, para a produtividade de grãos, enquanto, em Ponta Grossa, não se observou tendência semelhante, nos dois anos de experimentação.
4. A densidade de semeadura pode influenciar na massa de mil sementes, dependendo do ano e local.

5. O peso hectolítrico foi influenciado pelas condições de ambiente de cada ano e de locais dentro de cada ano.

6. O número de espigas por unidade de área apresentou incremento linear, com o aumento na densidade de semeadura, bem como foi influenciado pela interação entre ano e local de cultivo.

\section{REFERÊNCIAS}

BENIN, G. et al. Análises biplot na avaliação de cultivares de trigo em diferentes níveis de manejo. Bragantia, Campinas, v. 71, n. 1, p. 28-36, 2012.

CAIERÃO, E. et al. Análise da adaptabilidade e da estabilidade de genótipos de trigo como ferramenta auxiliar na indicação de novas cultivares. Ciência Rural, Santa Maria, v. 36, n. 4, p. 1112-1117, 2006.

CARGNIN, A. et al. Tolerância ao estresse térmico em genótipos de trigo. Pesquisa Agropecuária Brasileira, Brasília, DF, v. 41, n. 8, p. 1269-1276, 2006.

COMPANHIA NACIONAL DE ABASTECIMENTO (Conab). Acompanhamento da safra brasileira de grãos 2011/2012. 2012. Disponível em: <http://www.conab.gov. brlevantamento/conabweb/index.php?pag=27>. Acesso em: 20 jun. 2012.

CUNHA, G. R. da et al. Trigo. In: MONTEIRO, J. E. B. A. Agrometeorologia dos cultivos: o fator meteorológico na produção agrícola. Brasília, DF: Inmet, 2009. p. 279-293.

FIOREZE, S. L. et al. Tillering of two wheat genotypes as affected by phosphorus levels. Acta Scientiarum Agronomy, Maringá, v. 34, n. 3, p. 331-338, 2012.

FRANCESCHI, L. de et al. Métodos para análise de adaptabilidade e estabilidade em cultivares de trigo no Estado do Paraná. Bragantia, Campinas, v. 69, n. 4, p. 797-806, 2010.

GAJU, O. et al. Relationships between large-spike phenotype, grain number, and yield potential in spring wheat. Crop Science, Madison, v. 49, n. 3, p. 961-973, 2009.

GUARIENTI, E. M. et al. Efeitos da precipitação pluvial, da umidade relativa do ar e de excesso de déficit hídrico do solo no peso hectolitro, no peso de mil grãos e no rendimento de grãos de trigo. Ciência e Tecnologia de Alimentos, Campinas, v. 25, n. 3, p. 412-418, 2005. 
OZTURK, A. et al. Growth and yield response of facultative wheat to winter sowing, freezing sowing and spring sowing at different seeding rates. Journal of Agronomy and Crop Science, Malden, v. 192, n. 1, p. 1016, 2006.

SILVA, R. R. et al. Adaptabilidade e estabilidade de cultivares de trigo em diferentes épocas de semeadura, no Paraná. Pesquisa Agropecuária Brasileira, Brasília, DF, v. 46, n. 11, p. 1439-1447, 2011.

SILVEIRA, G. da et al. Efeito da densidade de semeadura e potencial de afilhamento sobre a adaptabilidade e estabilidade em trigo. Bragantia, Campinas, v. 69, n. 1, p. 63-70, 2010.

SPARKES, D. L. et al. Does light quality initiate tiller death in wheat? European Journal of Agronomy, Lancaster, v. 24, n. 3, p. 212-217, 2006.

UNITED STATES DEPARTMENT OF AGRICULTURE (USDA). Estatísticas de oferta e demanda mundial de commodities agrícolas. 2012. Disponível em: <http:// www.fas.usda.gov/psdonline>. Acesso em: 20 nov. 2012.
VALÉRIO, I. P. et al. Desenvolvimento de afilhos e componentes do rendimento em genótipos de trigo sob diferentes densidades de semeadura. Pesquisa Agropecuária Brasileira, Brasília, DF, v. 43, n. 3, p. 319-326, 2008.

VALÉRIO, I. P. et al. Fatores relacionados à produção e desenvolvimento de afilhos em trigo. Semina: Ciências Agrárias, Londrina, v. 30, supl. 1, p. 1207-1218, 2009.

VALÉRIO, I. P. et al. Seeding density in wheat: the more, the merrier? Scientia Agricola, Piracicaba, v. 70, n. 3, p. 176-184, 2013.

WHALEY, J. N. et al. The physiological response of winter wheat to reductions in plant density. Annals of Applied Biology, Malden, v. 137, n. 2, p. 164-177, 2000.

YAN, W.; HOLLAND, J. B. A Heritability-adjusted GGE biplot for test environment evaluation. Euphytica, Wageningen, v. 171, n. 3, p. 355-369, 2010.

ZAGONEL, J. et al. Doses de nitrogênio e densidades de plantas com e sem um regulador de crescimento afetando o trigo, cultivar OR-1. Ciência Rural, Santa Maria, v. 32, n. 1, p. 25-29, 2002. 